Heterogeneous Ozonolysis of Tetrahydrocannabinol: Implications for Thirdhand Cannabis Smoke

\author{
Aaron D. L. Wylie and Jonathan P. D. Abbatt* \\ Department of Chemistry, University of Toronto, 80 St. George Street, Toronto, ON, CA M5S \\ 3H6 \\ *Email correspondence to: jonathan.abbatt@utoronto.ca
}

This supporting information contains 12 pages, 8 figures and 7 tables, 1 text section. 


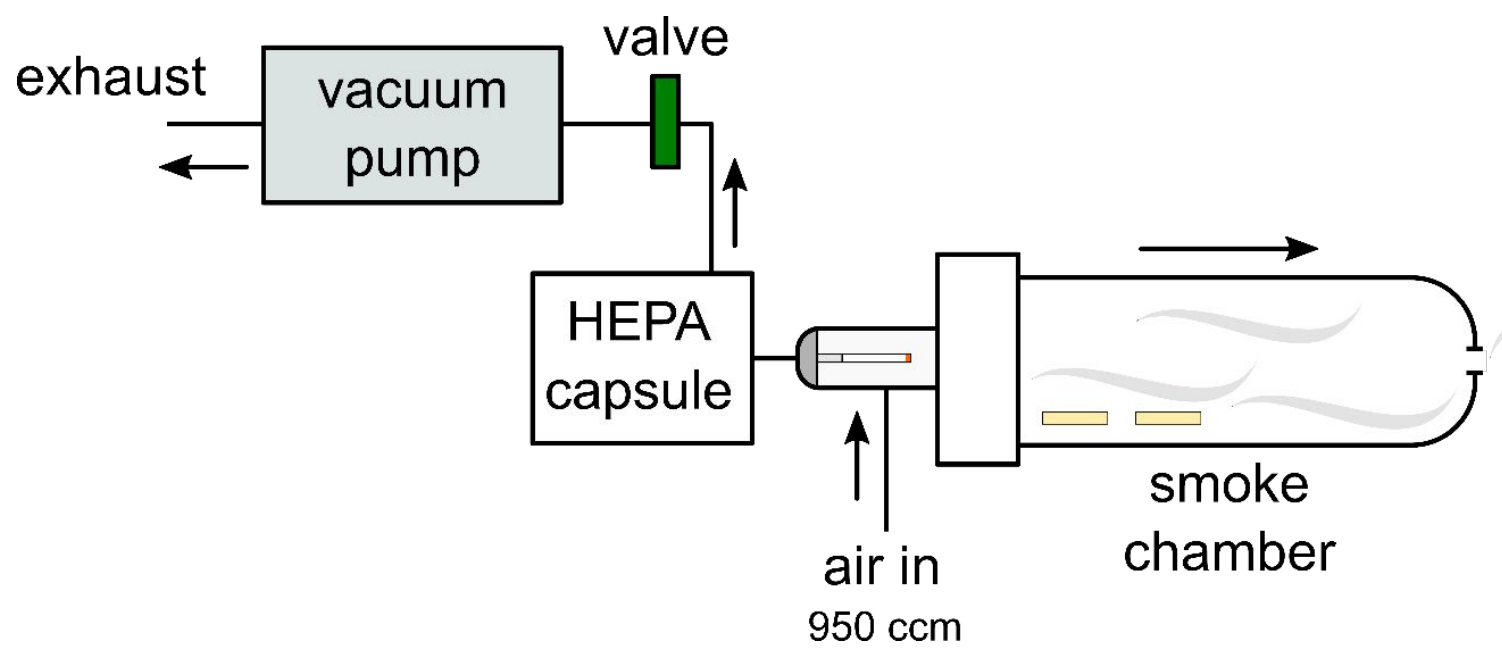

Figure S1. Smoke collection apparatus schematic. Pre-rolled cannabis cigarettes were mounted on a vacuum port next to an air flow. Opening the cigarette to vacuum allowed simulation of puffing, while the air flow carried produced smoke over surfaces where smoke is deposited.

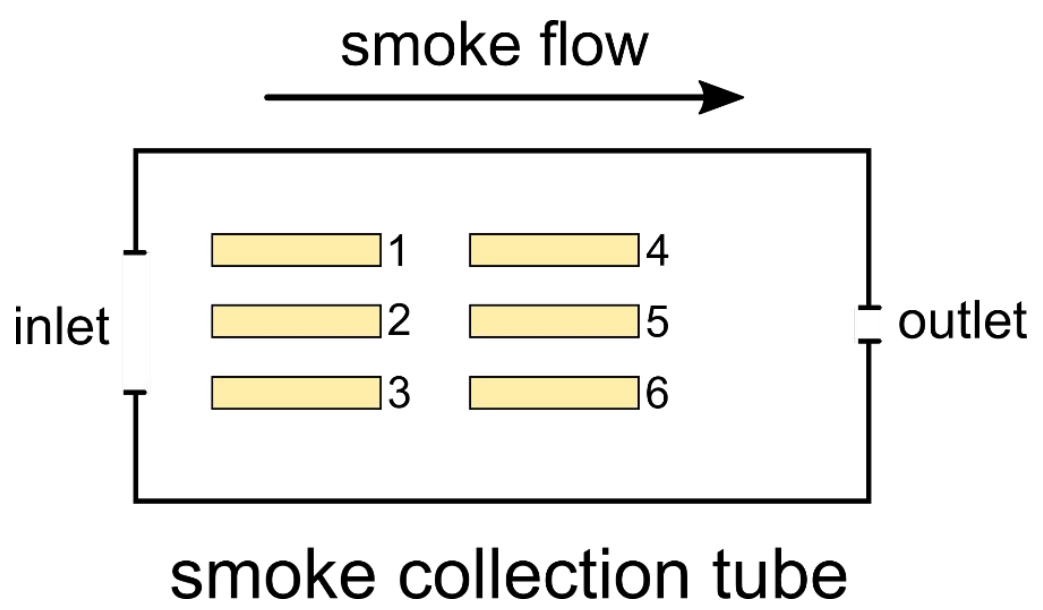

Figure S2. Cloth strip configuration in smoke collection tube. Strips were laid near the inlet of the tube, with spacing between each strip. 


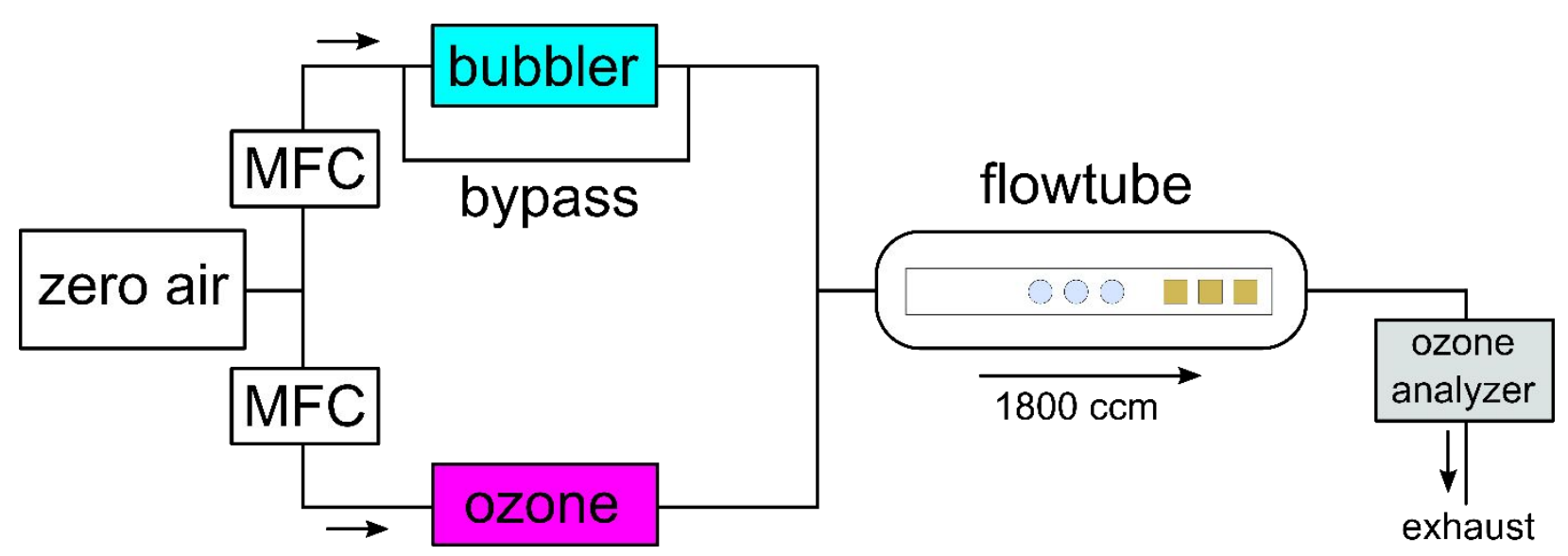

Figure S3. Schematic of experimental flow tube setup. Zero air is introduced and split into 2 channels where relative humidity and ozone concentration are controlled before recombining into the flow tube. Sample surfaces are laid on a PTFE bar near the end of the flow tube. MFC = mass flow controller. Ozone concentration was measured in the outflow of the flow tube. Glass flow tube dimensions were $60 \mathrm{~cm}$ length, $6 \mathrm{~cm}$ internal diameter. Circular glass microscope cover slides had a diameter of $18 \mathrm{~mm}$, and cotton cloth strips were $0.5 \times 4.5 \mathrm{~cm}$ each with a mass of $\sim 900 \mathrm{mg}$. The PTFE support bar was $61 \times 2.5 \times 0.32 \mathrm{~cm}$. Air flowrate through the flow tube was 1,800 ccm (cubic centimeters per minute). Glass slides were laid end-on-end beginning from a distance of $1 \mathrm{~cm}$ from the end of the PTFE bar, with a spacing of $0.5 \mathrm{~cm}$ between each. Cloth strips were laid end-on-end at a $45^{\circ}$ angle beginning from a distance of $1 \mathrm{~cm}$ from the end of the PTFE bar, with a spacing of $0.5 \mathrm{~cm}$ between each. A total of 9 samples were used per experiment. 


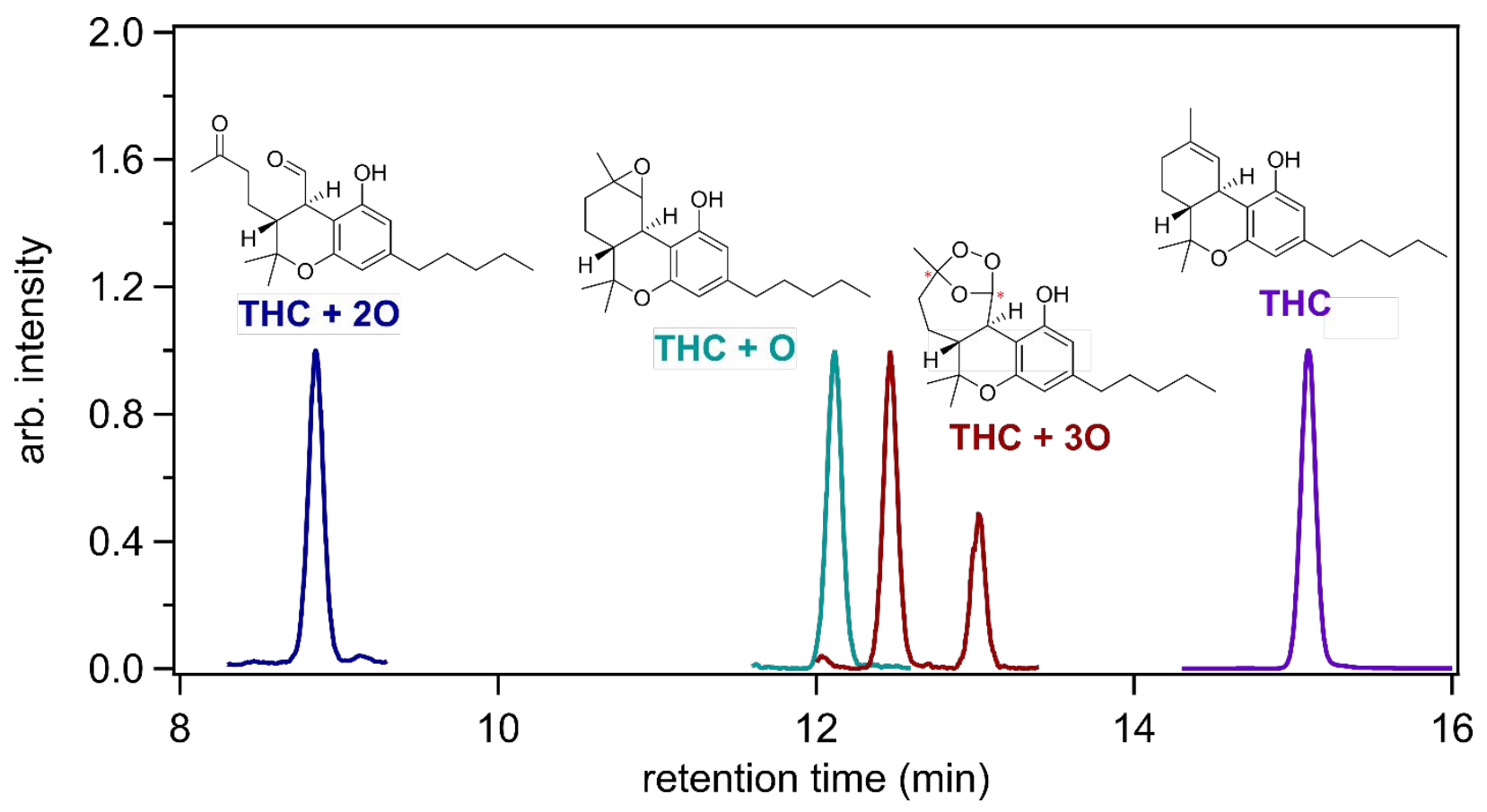

Figure S4. LC-MS/MS chromatogram for THC and ozonolysis products. Displayed are the extracted ion chromatograms for $\mathrm{THC}, \mathrm{THC}+\mathrm{O}, \mathrm{THC}+2 \mathrm{O}$ and $\mathrm{THC}+3 \mathrm{O}$ obtained after ozonolysis of authentic THC standard. THC $+\mathrm{O}$ is thought to be an epoxide, $\mathrm{THC}+2 \mathrm{O}$ a dicarbonyl and $\mathrm{THC}+3 \mathrm{O}$ a SOZ (structures shown). The SOZ is a double peak because of the diastereomeric centers (labelled with red stars). Peak heights of each respective species are normalized to 1 for clarity. 


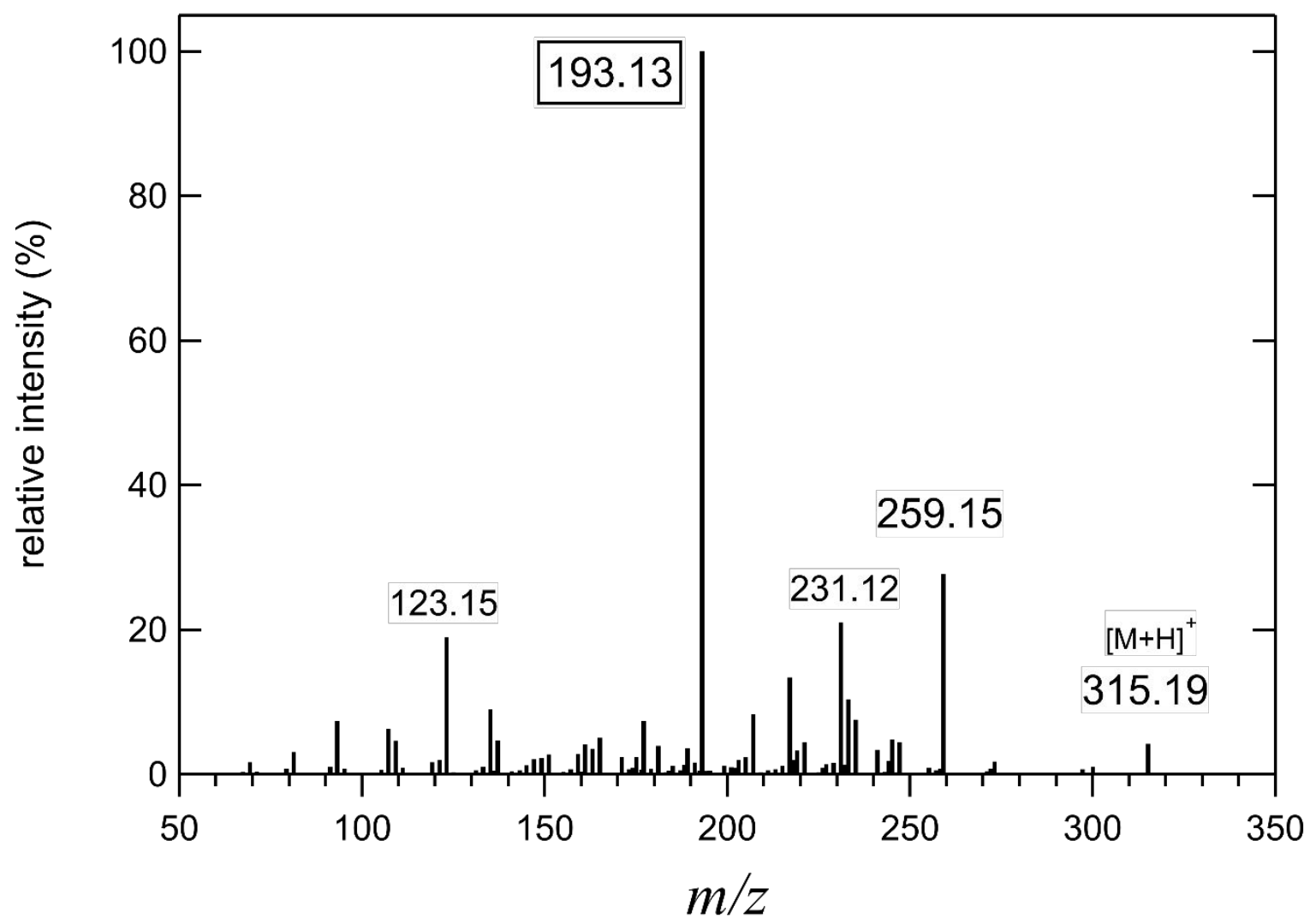

Figure S5. LC-MS/MS product ion spectrum of THC. Spectrum was collected with collision energy $=30 \mathrm{~V}$ in positive ion mode with collision gas $(\mathrm{Ar})$ pressure $=1.5 \mathrm{mTorr}$. Spectrum was obtained from an authentic THC standard. 


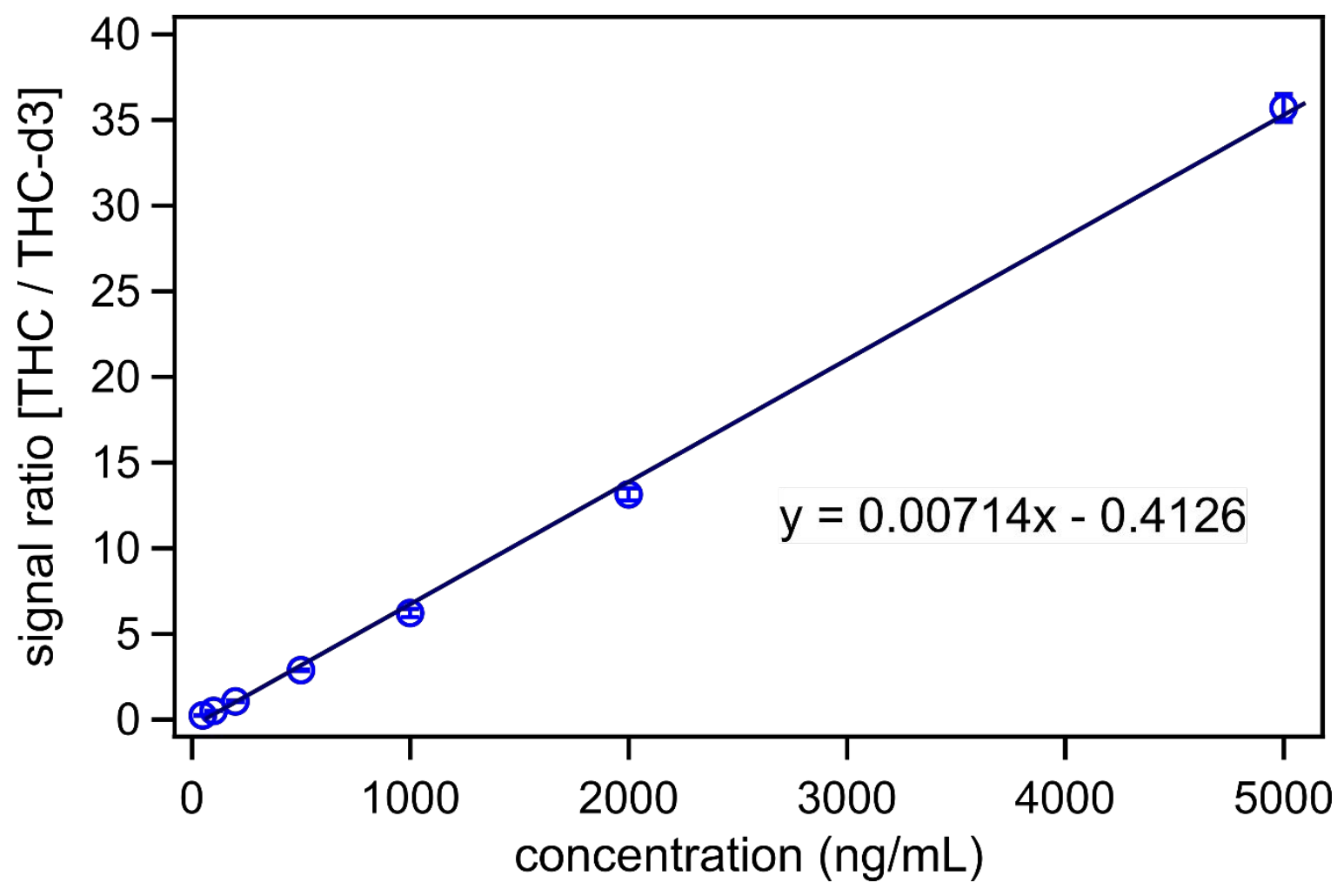

Figure S6. Calibration curve for LC-MS/MS quantitation of THC. Calibration curve was calculated with $x^{-1}$ weighting. THC is quantitated by its signal ratio to internal standard THC-d3. Internal standard concentration is $150 \mathrm{ng} \mathrm{mL}^{-1}$ with instrument injection volume of $5 \mu \mathrm{L}$. 

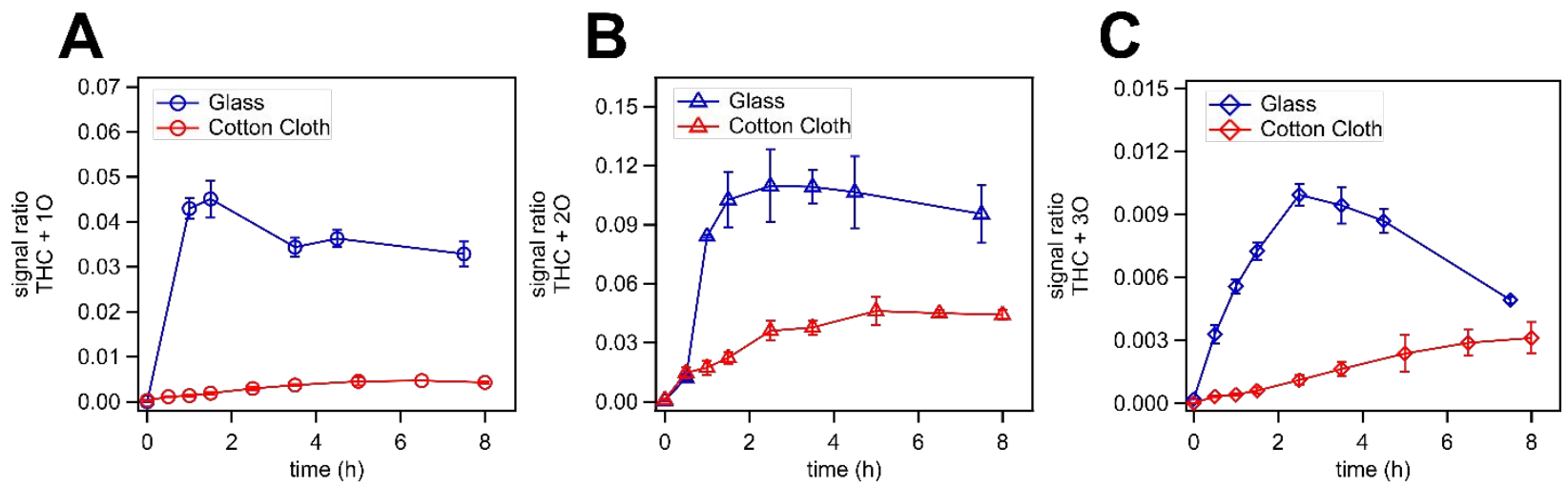

Figure S7. THC ozonolysis product formation signal ratios vs. time for the ozonolysis of THC at $100 \mathrm{ppb}_{3}$ on glass surfaces and cotton cloth surfaces, separated in frames $\mathrm{A}, \mathrm{B}$ and $\mathrm{C}$ for the three different products. All signal ratios are determined by normalizing product signals to the initial THC signal at time $=0$. Error bars indicate $\pm 1 \sigma$ from 3 replicate measurements. 


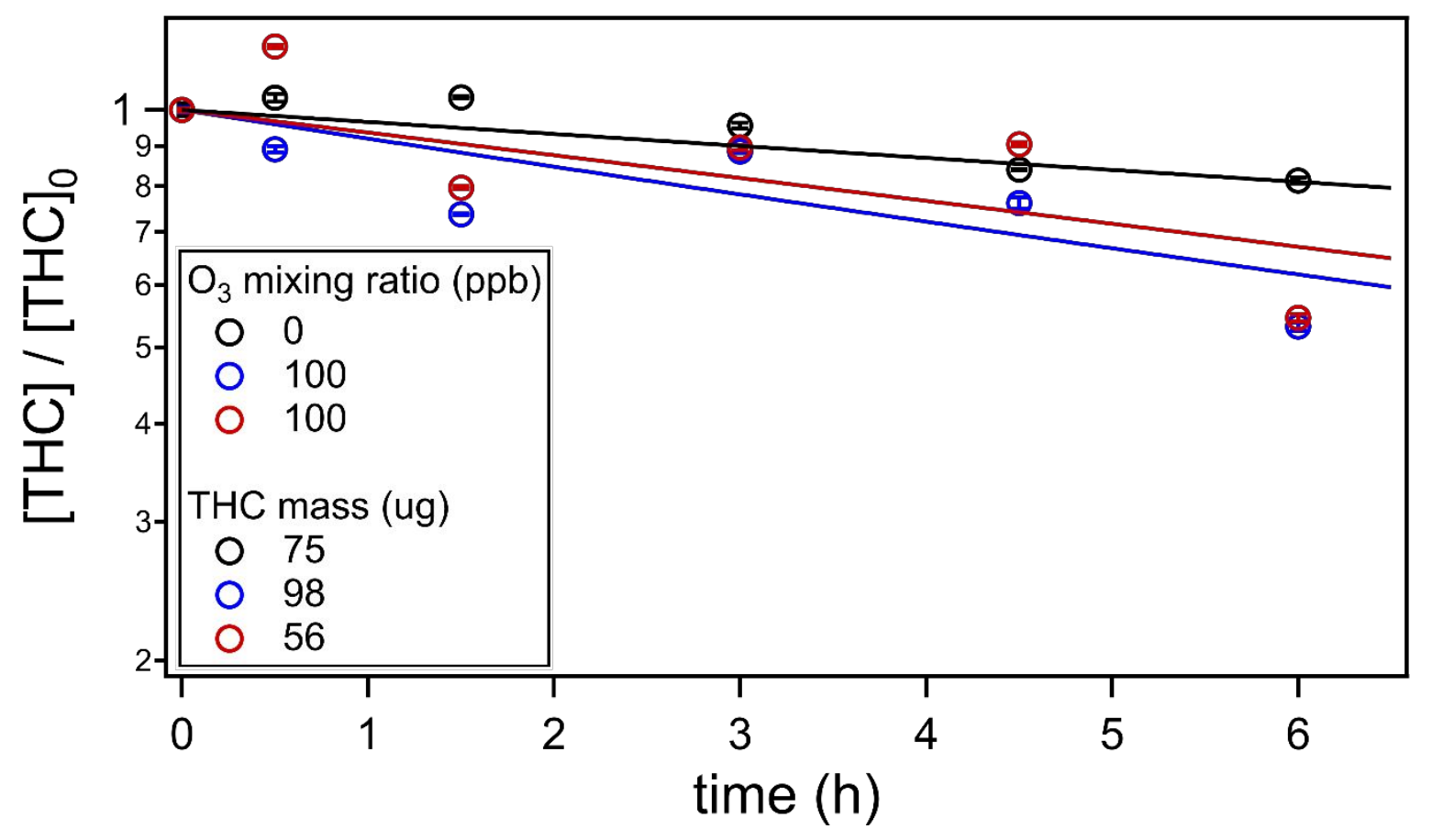

Figure S8. Relative [THC] vs time for the ozonolysis of THC within cannabis smoke on cotton cloth. Decay of THC is shown for exposure to $100 \mathrm{ppb} \mathrm{O}_{3}$, and two different smoke thicknesses characterized by the initial mass of THC present. The THC decay is slow because of the large amount of THC on the surface. 
Table S1. SRM table for THC, internal standard, and oxidation products.

\begin{tabular}{l|lllll} 
species & $\begin{array}{l}\text { precursor ion } \\
/ \mathbf{m} / \mathbf{z}\end{array}$ & $\begin{array}{l}\text { product ion } / \\
\mathbf{m} / \mathbf{z}\end{array}$ & $\mathbf{C E} / \mathbf{V}$ & $\mathbf{R T} / \mathbf{m i n}$ & $\begin{array}{l}\text { acquisition } \\
\text { window / } \mathbf{m i n}\end{array}$ \\
\hline $\mathrm{THC}+2 \mathrm{O}$ & 347 & 271 & 16 & 8.8 & 1 \\
$\mathrm{THC}+\mathrm{O}$ & 331 & 193 & 26 & 12.1 & 1 \\
$\mathrm{THC}+3 \mathrm{O}$ & 363 & 193 & 26 & 12.7 & 1.4 \\
$\mathrm{THC}$ & 315 & 193 & 22 & 15.3 & 2 \\
$\begin{array}{l}\text { THC-d3 } \\
\text { (IStd) }\end{array}$ & 318 & 196 & 22 & 15.3 & 2
\end{tabular}

Table S2. THC calibration parameters \& figures of merit.

\begin{tabular}{ll} 
calibration equation $^{\mathrm{a}}$ & $\mathbf{R}^{\mathbf{2}}$ \\
\hline$y=0.00714 x-0.4126$ & 0.9942
\end{tabular}

\begin{tabular}{ll|l}
\hline $\mathbf{L O D}^{\mathrm{b}}$ & method & $1.74 \mathrm{ng} \mathrm{mL}^{-1}$ \\
& on-column & $8.72 \mathrm{pg}$ \\
LOQ $^{\mathrm{c}}$ & method & $5.81 \mathrm{ng} \mathrm{mL}^{-1}$ \\
& on-column & $29.1 \mathrm{pg}$
\end{tabular}

a units of $y$ are signal / signal of $150 \mathrm{ng} \mathrm{mL}^{-1}$ internal standard, units of $x$ are $\mathrm{ng} \mathrm{mL} \mathrm{m}^{-1}$.

$\mathrm{b}$ determined as $3 \times \sigma / m$ from the lowest calibration level.

${ }^{c}$ determined as $10 \times \sigma / m$ from the lowest calibration level.

Table S3. Results of THC recovery from glass disc extraction.
THC film mass / $\mu \mathrm{g}$
$\%$ recovery
standard deviation $^{a}$ 


\begin{tabular}{l|rl}
0.4 & 93.4 & 1.7 \\
2.0 & 100.7 & 1.0 \\
4.0 & 98.9 & 1.2 \\
\hline
\end{tabular}

a $N=3$ sample replicates per concentration level.

Table S4. Results of THC recovery experiment from cloth strip extraction.

\begin{tabular}{rr|ll} 
THC mass on cloth $/ \boldsymbol{\mu g}$ & \% recovery & standard deviation $^{\mathbf{a}}$ \\
\hline 2 & 103.3 & 0.9 \\
5 & 105.9 & 2.8 \\
10 & 104.7 & 1.2 \\
\hline
\end{tabular}

a $N=3$ sample replicates per concentration level.

Table S5. Pseudo first-order rate constants $k^{\mathrm{I}}$ and effective second-order rate constants $k^{\mathrm{II}}$ for the heterogeneous ozonolysis of THC on glass discs and cotton cloth.

glass discs

\begin{tabular}{rr|cc} 
O $_{\mathbf{3}}$ mixing ratio / ppb & & $\times \mathbf{1 0}^{\mathbf{3}} \boldsymbol{k}^{\mathbf{I}} \pm \boldsymbol{\sigma}^{\mathbf{a}} / \mathbf{m i n}^{-\mathbf{1}}$ & $\times \mathbf{1 0}^{\mathbf{4}} \boldsymbol{k}^{\mathbf{I I}} \pm \boldsymbol{\sigma}^{\mathbf{b}} / \mathbf{p p b}^{-\mathbf{1}} \mathbf{~ m i n}^{\mathbf{- 1}}$ \\
\hline 25 & $5.7 \pm 0.2$ & $2.4 \pm 0.5$ \\
50 & $11 \quad \pm 0.1$ & \\
100 & $27 \quad \pm 0.4$ & \\
200 & $53 \quad \pm 0.6$ & \\
\hline
\end{tabular}

\section{cotton cloth}

\begin{tabular}{rr|ll}
$\mathbf{O}_{\mathbf{3}}$ mixing ratio / ppb & & $\times \mathbf{1 0}^{\mathbf{3}} \boldsymbol{k}^{\mathbf{I}} \pm \boldsymbol{\sigma}^{\mathbf{a}} / \mathbf{m i n}^{\mathbf{- 1}}$ & $\times \mathbf{1 0}^{\mathbf{5}} \boldsymbol{k}^{\mathbf{I}} \pm \boldsymbol{\sigma}^{\mathbf{b}} / \mathbf{p p b}^{\mathbf{- 1}} \mathbf{m i n}^{\mathbf{- 1}}$ \\
\hline 25 & $0.81 \pm 0.2$ & $2.9 \pm 1.7$ \\
50 & $1.3 \pm 0.1$ & \\
100 & $2.9 \pm 0.3$ & \\
200 & $6.1 \pm 0.1$ & \\
\hline
\end{tabular}

a determined from $\sigma$ of exponential curve fit.

b determined from $\sigma$ of all trials plus sum of $\sigma$ from each trial. 
Table S6. Pseudo first-order rate constants for the heterogeneous $\mathrm{THC}-\mathrm{O}_{3}$ reaction under varying film thickness.

\begin{tabular}{rr|l} 
average film thickness / nm & $\times \mathbf{1 0}^{\mathbf{3}} \boldsymbol{k}^{\mathbf{I}} \pm \boldsymbol{\sigma}^{\mathbf{a}} / \mathbf{~ m i n}^{-\mathbf{1}}$ \\
\hline 7.5 & $16.6 \pm 0.07$ \\
15 & $15.1 \pm 0.17$ \\
30 & $9.2 \pm 0.13$
\end{tabular}

a determined from $\sigma$ of exponential curve fit.

Table S7. Determined pseudo first-order and second-order rate constants for the heterogeneous $\mathrm{THC}-\mathrm{O}_{3}$ reaction in cannabis smoke.

\begin{tabular}{r|r|rr}
{$\left[\mathbf{O}_{3}\right] / \mathbf{p p b}$} & initial THC mass $/ \boldsymbol{\mu g}$ & $\times \mathbf{1 0}^{\mathbf{3}} \boldsymbol{k}^{\mathbf{I}} \pm \boldsymbol{\sigma}^{\mathbf{a}} / \mathbf{m i n}^{-\mathbf{1}}$ & $\begin{array}{l}\times \mathbf{1 0}^{\mathbf{5}} \boldsymbol{k}^{\mathbf{I I}} \pm \boldsymbol{\sigma} / \mathbf{p p b}^{\mathbf{- 1}} \mathbf{m i n}^{-\mathbf{1}} \\
\mathbf{b}\end{array}$ \\
\hline 0 & $\sim 75$ & $0.58 \pm 0.01$ & - \\
100 & $\sim 56$ & $1.1 \pm 0.4$ & $1.1 \pm 0.4$ \\
100 & $\sim 98$ & $1.6 \pm 0.8$ & $1.6 \pm 0.8$ \\
\hline
\end{tabular}

a determined from $\sigma$ of exponential curve fit.

b determined by assuming first-order $\left[\mathrm{O}_{3}\right]$ dependence.

\section{Deposition Velocity Estimate}

An ozone deposition velocity can be estimated from the rate of THC loss on the glass surfaces, i.e. $2.4 \times 10^{-4}$ $\mathrm{min}^{-1} \mathrm{ppb}^{-1}$. This assumes that one ozone molecule consumes one THC molecule. For the size of the glass 
discs, the amount of THC on the glass disks $(4 \mu \mathrm{g})$ corresponds to $5.0 \times 10^{-9} \mathrm{moles}^{-2}$. Multiplying these two quantities together yields the flux of ozone to the THC surfaces per ppb of ozone: $2.0 \times 10^{-14} \mathrm{~mol} \mathrm{~cm}^{-2}$ $\mathrm{ppb}^{-1} \mathrm{~s}^{-1}$. Converting moles to molecules, and $\mathrm{ppb}$ to molecules $\mathrm{cm}^{-3}$ gives a deposition velocity of $0.5 \mathrm{~cm}$ $\mathrm{s}^{-1}$.

The deposition velocity can be used to gauge whether the rate of uptake to a surface is largely controlled by the rate of the chemistry on the surface or by mass transfer in the gas phase. In particular, in Cano-Ruiz et al. (1993), a relationship between the surface uptake coefficient and the deposition velocity is developed for different rates of turbulence/mixing in the gas phase. For a deposition velocity of $0.5 \mathrm{~cm} \mathrm{~s}^{-1}$, Cano-Ruiz et al. (e.g. Figure 5 of their paper) illustrate that for most mixing conditions in the gas phase, the results lie in the transition regime between being fully controlled by chemistry (as they would be for very low uptake coefficients of, say, $10^{-6}$ and below) or fully controlled by gas phase mass transfer (as they would be for uptake coefficients of $10^{-3}$ and larger).

References:

Cano-Ruiz et al., Atmospheric Environment, 27A, 2039-2050, 1993. 